\title{
Salt stress impacts on seed germination and seedling growth of Brassica napus $\mathbf{L}$.
}

\author{
Nazima Batool ${ }^{* 1}$, Tahira Noor ${ }^{2}$, Noshin Ilyas ${ }^{1}$ and Armghan Shahzad ${ }^{2}$ \\ 1. Depertment of Botany, Pir Mehr Ali Shah Arid Agriculture University, Rawalpindi, Pakistan. \\ 2. National Institute for Genomics and Advanced Biotechnology, (NARC), Islamabad, Pakistan. \\ *Corresponding author's email: nazimabatool@gmail.com \\ Citation \\ Nazima Batool ${ }^{1}$, Tahira Noor, Noshin Ilyas and Armghan Shahzad. Salt stress impacts on Seed germination and \\ seedling growth of Brassica napus L.. Pure and Applied Biology. Vol. 4, Issue 3, 2015, pp 398-406.
} http://dx.doi.org/10.19045/bspab.2015.43016

Received: 15/06/2015 $\quad$ Revised: 11/07/2015

Accepted: $23 / 07 / 2015$

\section{Abstract}

Crop plant germination and growth adversely affected through salt stress. Canola seed germination and seedling growth in saline condition was evaluated in a laboratory experiment. In sterilized petri plates seeds of two canola varieties (Bulbul 2000 and Rainbow) were sown. Saline condition was employed through sodium chloride solutions $(50 \mathrm{mM}, 75 \mathrm{mM}, 100 \mathrm{mM}$, $125 \mathrm{mM}$ and $150 \mathrm{mM}$ ) and distilled water control was sustained for comparison. Canola seed germination and seedling growth related attribute data were recorded. Results show that canola varieties were statistically significant $(\mathrm{P}<0.005)$ responses to saline conditions. Sodium chloride concentration gradual increase reduces canola seed final germination percentage, germination index, mean daily germination and seedling vigor index in both varieties. However, the high salt level $(100,125,150 \mathrm{~mm})$ significantly reduces germination parameters of seeds of Bulbul 2000. High salt levels significantly affect the root length, shoot length, fresh, and dry weight and total chlorophyll content. Rainbow show better germination and seedling growth in high salt levels. Therefore, they possibly will tolerate moderate levels of salt.

Key words: Salt stress; Canola; Seedling growth; Chlorophyll content.

\section{Introduction}

Abiotic stresses adversely affect the growth and yield of crop plants. Crop plants yield subsequently depends upon early seedling growth stages those most likely to more sensitive to abiotic stress conditions [1]. Abiotic stress is the primary factor for crop loss and globally $50 \%$ reduction in the standard yields [2]. Salt stress is major abiotic stresses that adversely influence plant growth and development. Salinity induces negative effects on germination parameter and seedling growth depending upon the plant species. Crop plants seed germination and early seedling growth are the stages more susceptible to high salt concentrations [3, 4]. Scientists' findings show that in saline environment ionic and osmotic effects disturbed plant germination process. Canola (Brassica napus L.) stands third after soybean and palm among oil crops all over the world. It produces as much as $14.7 \%$ of vegetable edible oil with high content of unsaturated fatty acids [5]. Canola is most important oil seed crop in Pakistan. Salt stress induced oxidative stress, which might be a reason for the germination percentage reduction [6]. Canola is moderately salt tolerant oil seed crop but canola crop growth increasing in 
past decades. This increase in canola plantation is needed to improve salt tolerance in canola crop. In Pakistan problem of salt stress is in irrigated agriculture where drainage is insufficient and almost 10 million ha area is badly affected through high salt concentrations [7]. This information is essential to suggest a suitable crop cultivar for saline soil and capability of crop plants to withstand and grow in salt affected soil is an immense achievement in agriculture [8]. The objective of the present study is to identify the impact of salt stress on different canola varieties at germination stage.

\section{Materials and Methods}

A laboratory experiment was carried out in plant physiology lab of department of botany at PMAS-Arid Agriculture University Rawalpindi to study the effect of salt stress on germination and seedling growth attributes of seeds of canola (Bulbul 2000 and Rainbow). Seeds of each variety were surface sterilized in a sodium hypochlorite $(1 \%)$ solution for $10 \mathrm{~min}$ and then washed twice with distilled water. After seed sterilization, Petri plates containing double layer filter paper were moistened and ten seeds of each variety were soaked in these Petri plates and then kept in an incubator ( $40 \%$ relative humidity) at $25^{\circ} \mathrm{C}$. Salt conditions were created by using aqueous sodium chloride solutions, for this point analytical grade $\mathrm{NaCl}$ dissolved in distilled water and prepare $50 \mathrm{mM}, 75 \mathrm{mM}$, $100 \mathrm{mM}, \quad 125 \mathrm{mM}$ and $150 \mathrm{mM}$ concentration solution. A distilled water control runs for evaluation purpose. Each treatment was replicated three times and germination rate were measured daily. Seeds were considered to be germinated when radical length exceeded $5 \mathrm{~mm}$ [9].

Germination percentage calculated by using the following formula.

Germination $\%$ age $=$ Total seeds germinated /Total no of seeds planted x 100
Germination index was calculated using following formula [10]

Germination Index $=n / d$; where $n=$ no of seedlings emerged on day and $\mathrm{d}=$ days after planting.

Mean Daily Germination was calculated through [11].

MDG = Final germination percentage / number of days to final germination.

Seedling vigor index was calculated using this equation [12]

$\mathrm{S}$. V. I = Seedling length $(\mathrm{cm}) \times$ germination $\%$ age

Where; germination $\%$ age $=$ Total seeds germinated /Total no of seeds planted x 100 . After 12 day of sowing from each treatment three seedlings were randomly selected used to measure root and shoot length. Digital balance was used to record seedling fresh and dry weight and seedlings were oven dried at $70^{\circ} \mathrm{C}$ for $48 \mathrm{~h}$ for dry weight. Total chlorophyll was recorded for each treatment [13]. For statistical analysis Statistics 8.1 program was used.

\section{Results and Discussion}

High sodium chloride levels in soil harmfully influence germination parameters of the canola cultivars. In different germination attributes significant $(p \leq 0.05)$ difference were observed between all salt levels and canola genotypes. Furthermore, canola varieties show different reactions to all salt levels as significant interaction $(p \leq$ 0.05) among factors. The germination percentage decreased with increasing salt levels (Figure 1), although germination establishment delayed in canola varieties. In Bulbul 2000 considerable impediment in germination was observed at higher salt level $150 \mathrm{mM}$. Germination index (Figure 2) and Mean daily germination (Figure 3 ) was observed that showed variation among both genotypes. As the salt level increase GP MDG and GI rate decreased. 


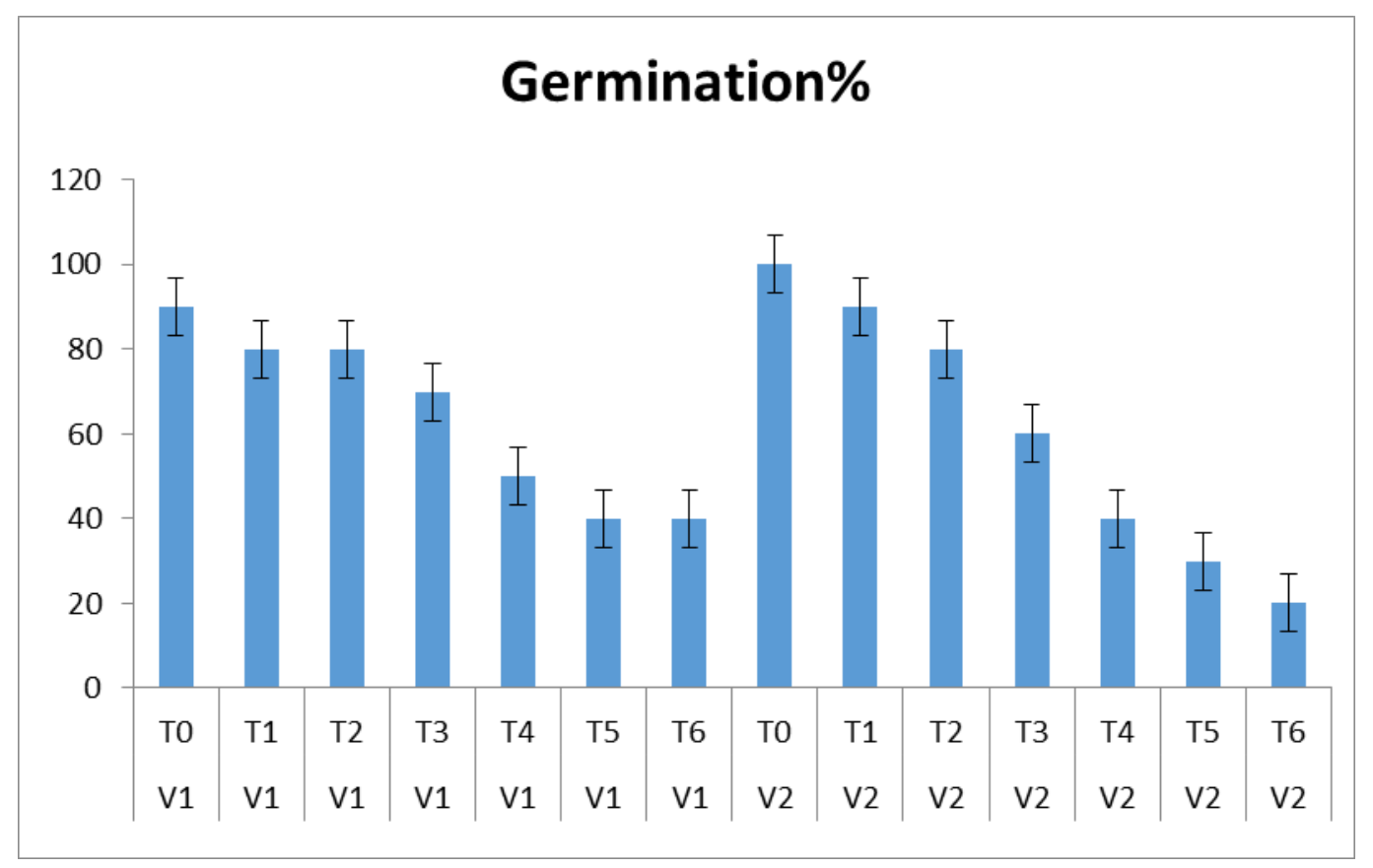

Figure 1. Effect of salt stress on seed germination of canola cultivars

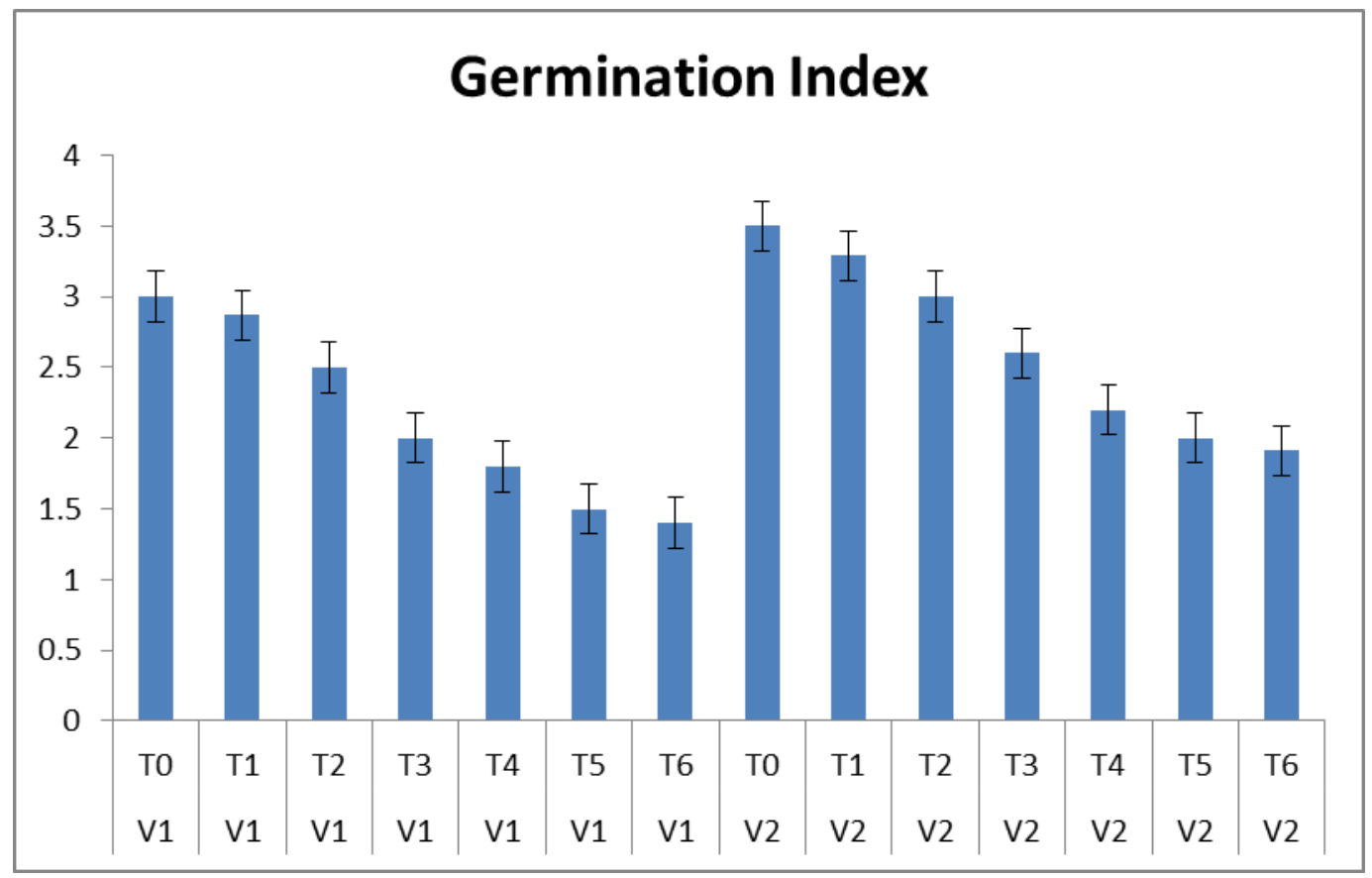

Figure 2. Effect of salt stress on germination index of canola cultivars 


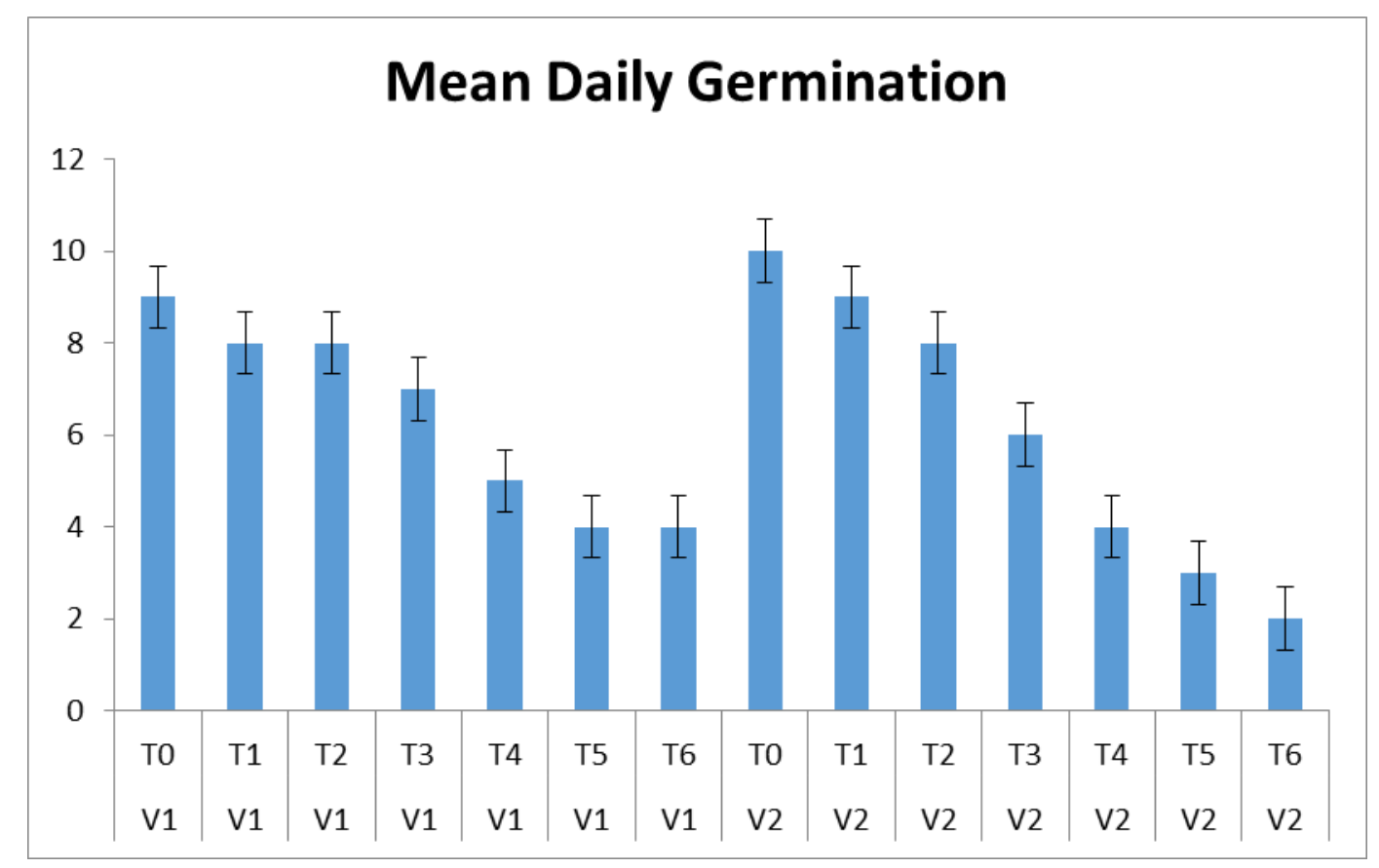

Figure 3. Effect of salt stress on mean daily germination of canola cultivars

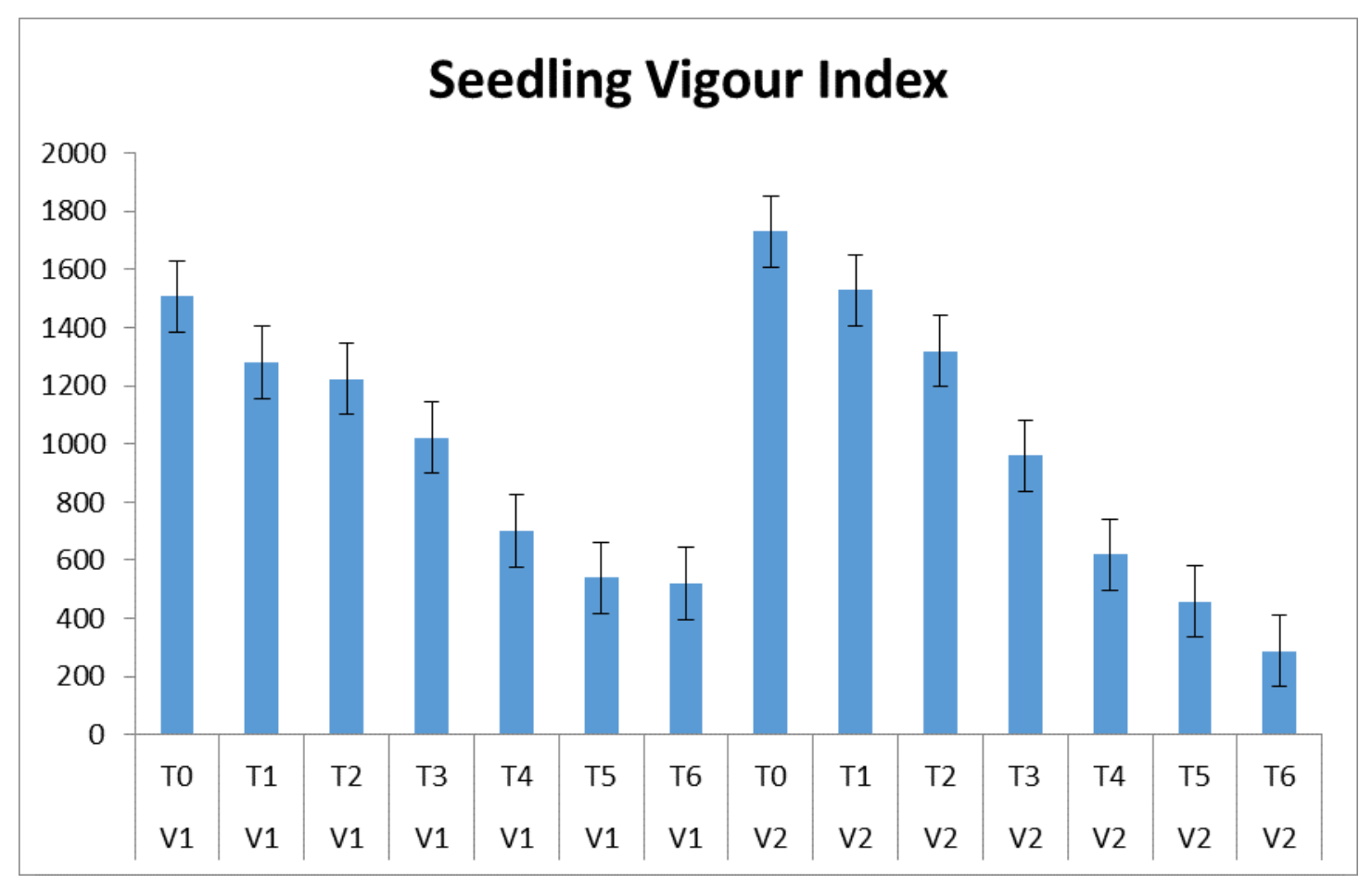

Figure 4. Effect of salt stress on seedling vigour index of canola cultivars 


\section{Shoot length}

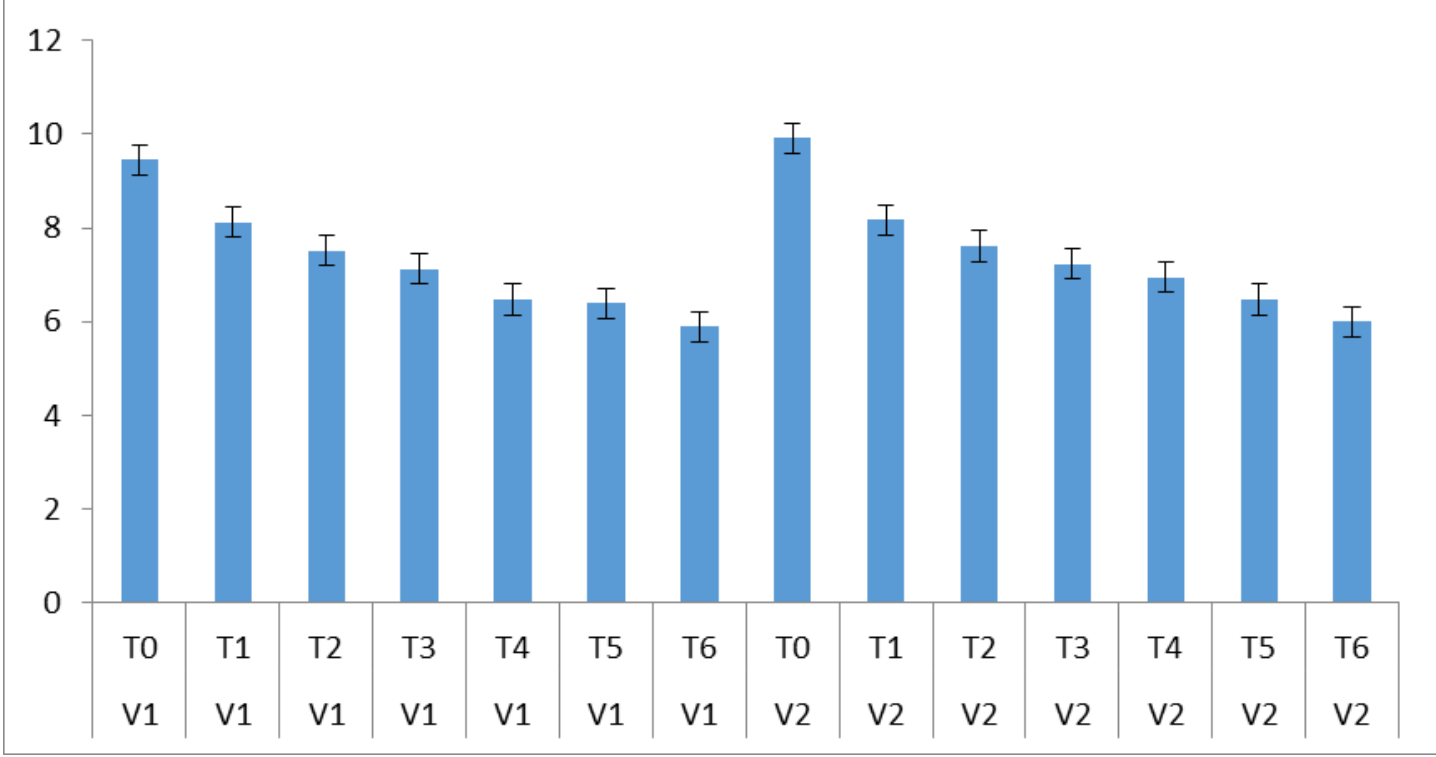

Figure 5. Effect of salt stress on shoot length of canola cultivars seedlings

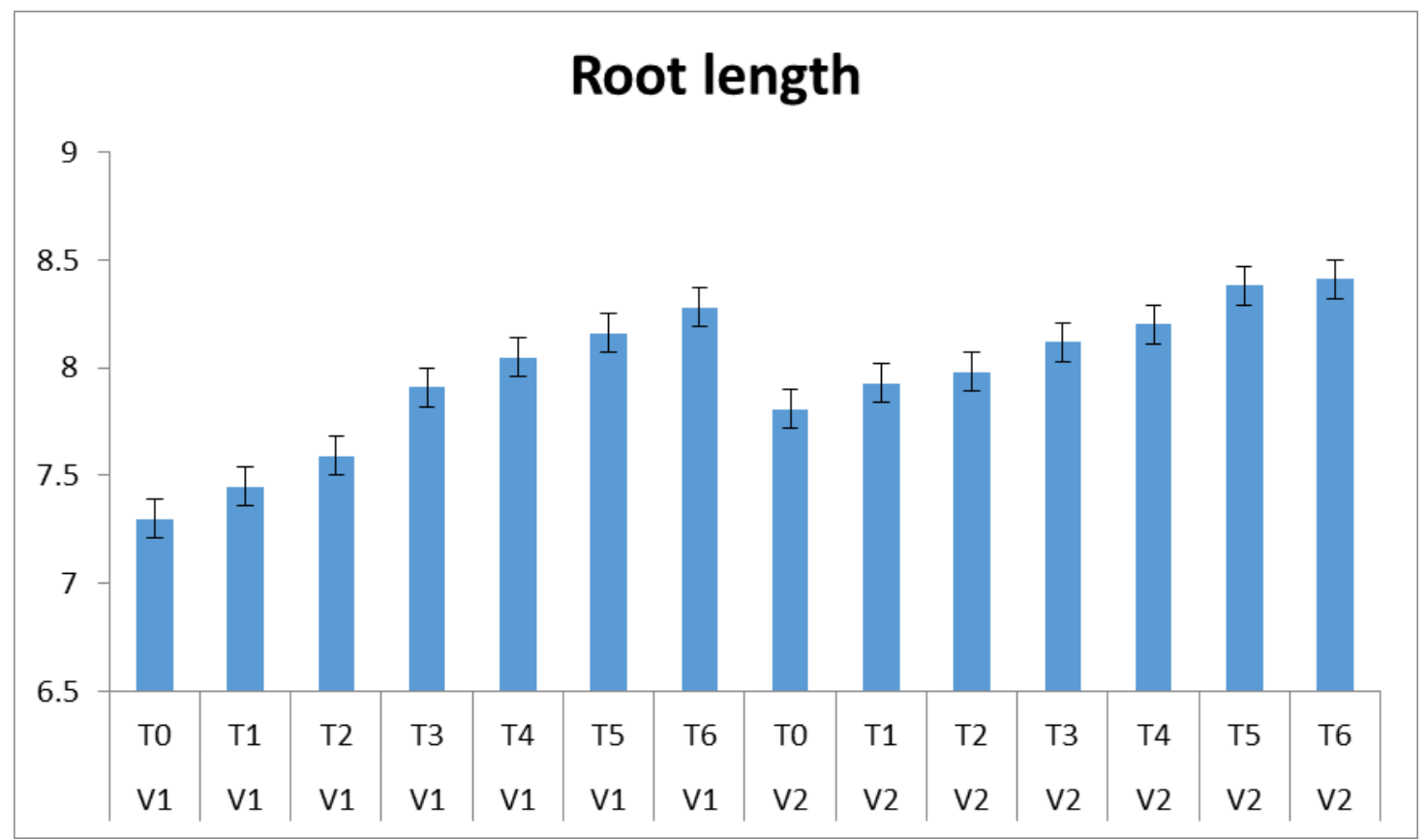

Figure 6. Effect of salt stress on root length of canola cultivars seedlings 


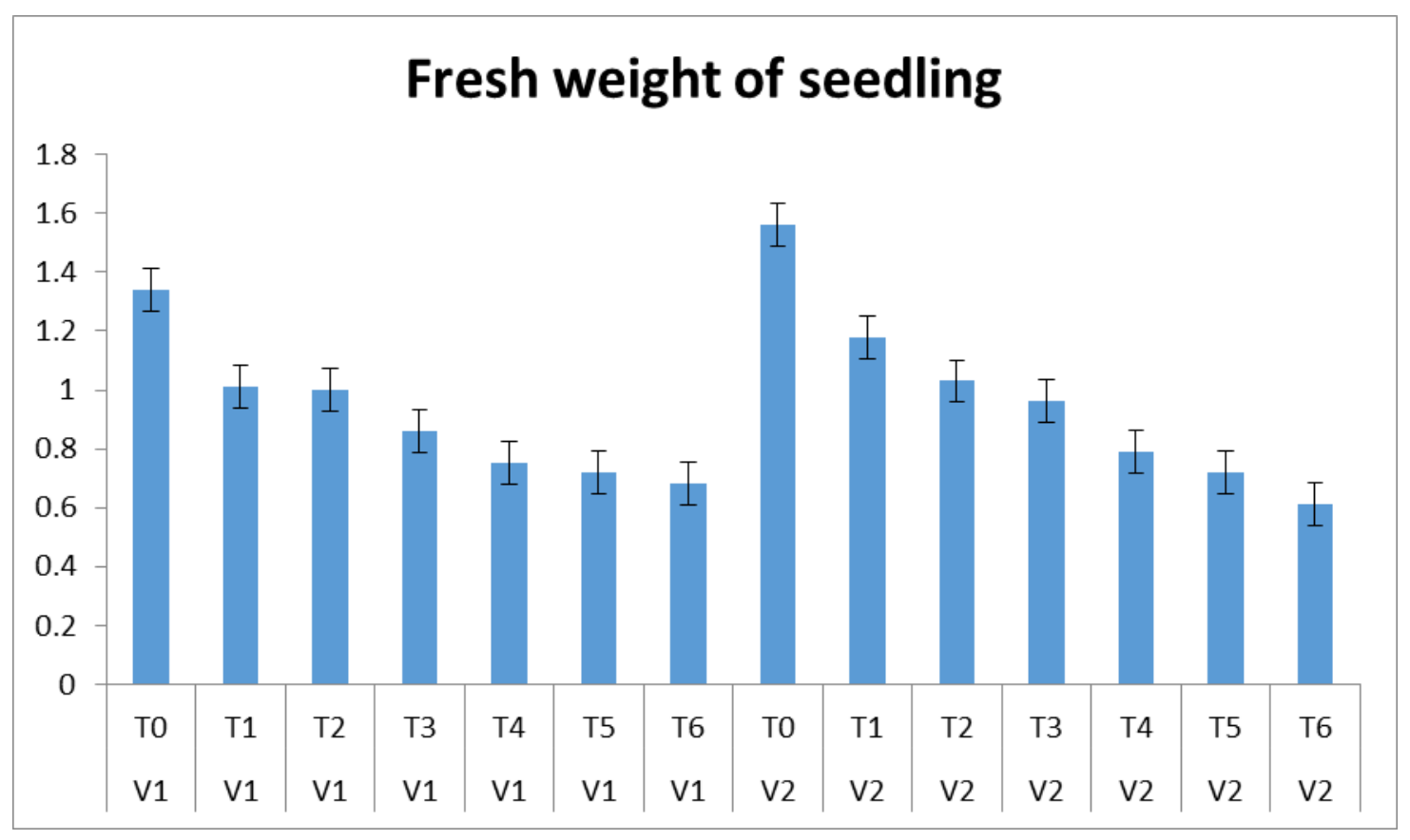

Figure 7. Effect of salt stress on fresh weight of canola cultivars seedlings

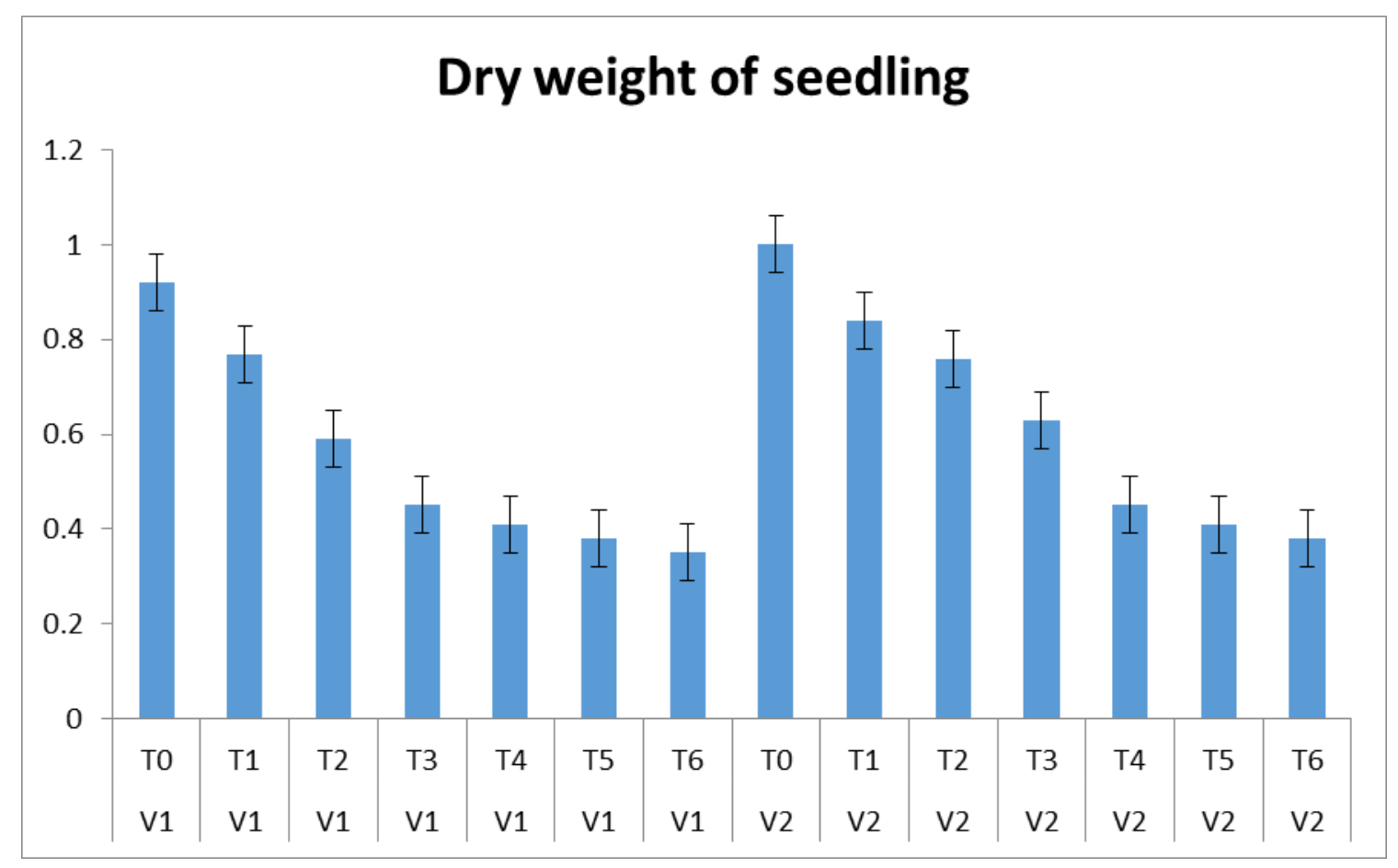

Figure 8. Effect of salt stress on dry weight of canola cultivars seedlings 


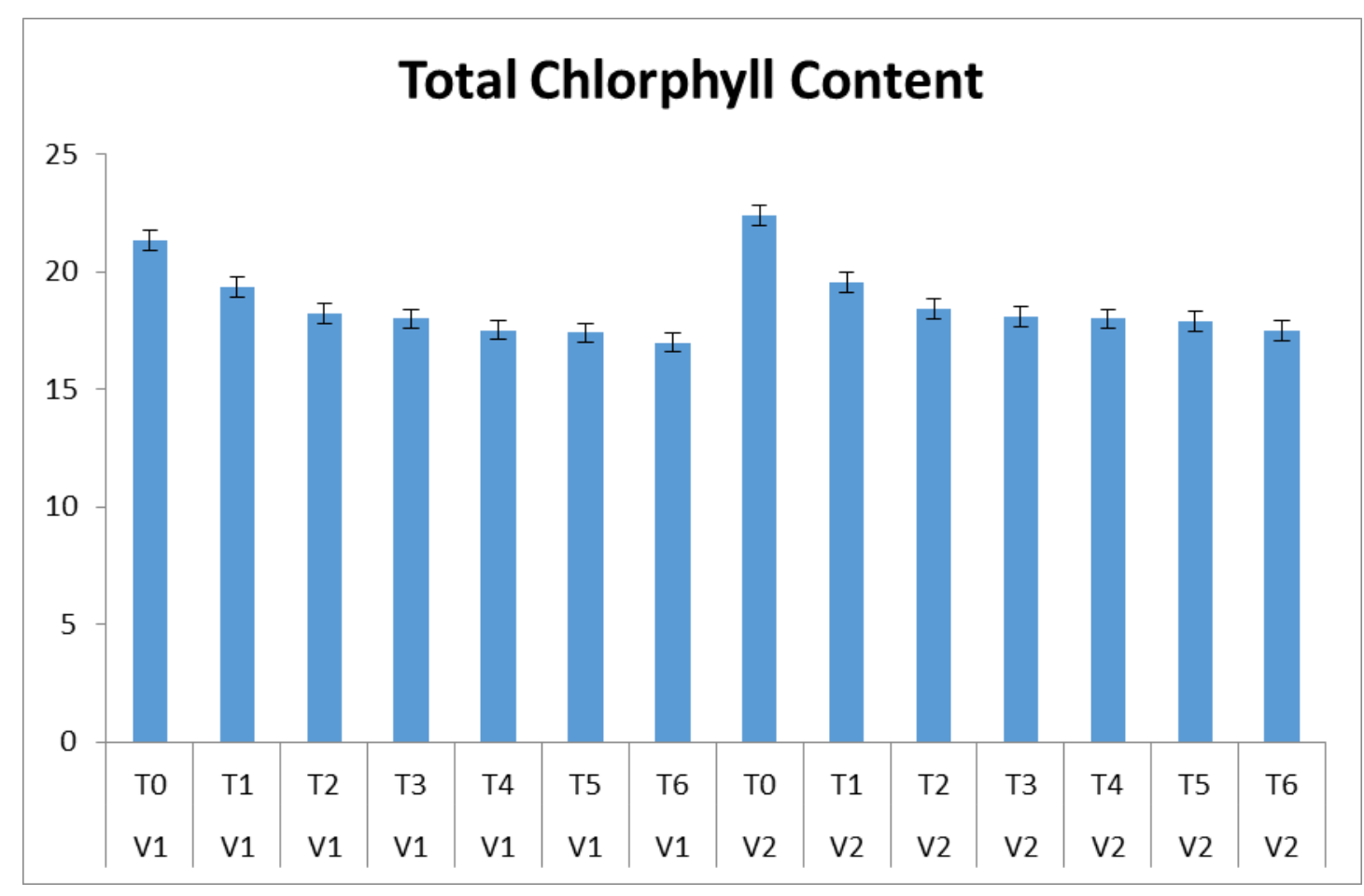

Figure 9. Effect of salt stress on total chlorophyll content of canola cultivars

At higher salt levels GP, MDG and GI was suppressed by 2, 3 and 4 days of seed germination in Bulbul 2000 as compared to control (Figure 1, 2 \& 3). However Rainbow shows better growth at higher salt. Similarly, Seedling vigour index (SVI) of both canola cultivars was observed at different salt levels (Figure 4). Saline conditions impaired seed germination, as a result the establishment of plant decreased. The harmful effect of salt stress on germination parameter of different plants has been studied by a number of scientists $[14,15]$. AOAC, [16] reported that reduction in germination percentage in saline conditions due to the combined effect of the osmotic and toxic effect of high salt levels [17]. Karamursel et al., [18] reported that high salt accumulation in inter and intracellular space drastically decrease the germination percentage primarily due to changes in water relations. Seed germination delay in high salt levels may be due to embryo damage by sodium, chloride ions, inhibition of seed, water uptake and exosmosis [19]. In seedling vigor index (SVI) obvious decrease was observed, seedling vigor index decreased strangely with increasing the salt level than the control. Salt tolerant canola genotypes show sodium and chloride compartmentalization at the organ and organelle level as compared salt-sensitive ones [3]. In this study both varieties were appeared to more sensitive to higher salt levels (100, 125 and $150 \mathrm{mM}$ ) than low concentration of salt. They depict better aptitude to deal with high salt levels. High salt levels gradually reduce seedling growth so that a harmful association was 
found among seedling growth and salt stress (Figure 5, 6, 7, 8 \& 9). Canola genotype interaction with different salt levels was significant $(p \leq 0.05)$. In all seedling growth parameters considerable differences were recorded between salt levels and canola varieties. Increasing salt levels subdued the shoot length of both varieties over control. Root length shows considerable increase with increasing salt levels. Root and shoot lengths are mainly significant attributes in saline condition because roots play important role in water absorption and minerals. Shoot provide support and supply nutrients, minerals and food for the rest of the plant. Therefore, root and shoot parameters gave main evidence about the plants response to salinity [20]. As the sodium chloride level increased their gradual reduction in fresh and dry weight of wheat seedling was recorded (Figure $7 \& 8$ ). In total chlorophyll content differences between canola varieties and salt level being statistically significant $(\mathrm{p} \leq 0.05)$ and comparable trend was recorded by other authors [21]. Plants seedling growth stages are very sensitive from salt stress because salinity alters plant water relation and ionic stress. A marked decline in total chlorophyll recorded in both cultivars and maximum in Bulbul 2000. Salt stress is known to cause decrease to chlorophyll content in canola and degradation of chlorophyll due to elimination of phytol caused by enhanced activity of chlorophyllase [22, 23]. Salt stress is responsible to generate oxidative stress resulting to alter cell ultra-structures [24, 25]. In present research Bulbul 2000 comparatively appear salt susceptible as compared to rainbow.

\section{References}

1. Malik MN (2006). Horiculture. Fruit crops. Plums. National book foundation; Islamabad. 474-76p.

2. Son F (2010). Determination on quality characteristics of some important Japanese plum (Prunus Salicina Lindl.) cultivars grown in Mersin-Turkey. African J Agri Res 5(10): 1144-1146.

3. Liu W (2007). Genetic Diversity and Phylogenetic Relationships among Plum Germplasm Resources in China Assessed with Inter-simple Sequence Repeat. Markers. 132(5): 619-628.

4. Agri. Stat. Pak (2010-11). Plums. Ministry for Food, Agriculture and Livestock, Economic Wing, Islamabad, Pakistan. Table 53. P. 97.

5. GOP (2009). Agricultural Statistics of Pakistan. District wise Area and Production of Plums. EconomicWing, Islamabad. 190-191p.

6. Rauf MA, Khan A and Rehman KU (2010-2011). Annual progress report. Agri. Res. Institute Mingora Swat. 1-2.

7. Chandler WH (1965). Deciduous orchards. Stone fruits. Plums. lea and febiger. 4(17): 338-352pp.

8. Grzyb ZS, Rozpara E (2000). Modern plum growing. Hortpress.

9. Kayano S, Kikuzaki H, Fukutsaka N, Mitani T and Nakatani N (2002). Antioxidant activity of prune (Prunus domestica L.) constituents and a new synergist. J Agric Food Chem 50: 37083712.

10. Kader AA and Mitchell FG (1989a). Maturity and quality. Peaches, plums and nectarines: growing and handling for fresh market. Uni California Depart Agri Nat Res 3331: 191-196.

11. Roper TR, Mahar DL and Mcmanus PS (1998). Harvesting. Growing apricots, cherries, peaches and plums in Wisconsin. Cooperative Extension. Univ. Wisconsin. A3639: P. 13. 
12. Crisosto $\mathrm{CH}$, Garner D, Crisosto GM and Bowerman E (2004). Increasing 'Blackamber' plum (Prunus salicina L) consumer acceptance. Postharvest Biol Technol 34: 237-244.

13. Zuzunaga M, Serrano M, MartınezRomero D, Valero D and Riquelme F (2001). Comparative study of two plum (Prunus salicina Lindl.) cultivars during growth and ripening. Food Sci Tech Int 7: 123-130.

14. Taylor MA, Rabe E, Dodd MC, and Jacobs G (1993). Influence of sampling date and position in the tree on mineral nutrients, maturity and gel breakdown in cold stored 'Songold' plums. Sci Hort 54: 131-141.

15. Crisosto $\mathrm{CH}$, Mitchell FG, Johnson S (1995). Factors in fresh market stone fruit quality. Postharvest News Inf 6: 17-21.

16. AOAC (1995). Official methods of analysis $\left(16^{\text {th }}\right.$ ed). Washington, DC: Association of Official Analytical Chemists.

17. Steel RGD and Torrie JH (1980). Principles and procedures of statistics, second edidtion, New York: McGraw-Hill.

18. Karamursel OF, Sevik I, Sarisi HC, Kocal H and Ozturk FP (2007). Adaptation of European plums (Prunus domestica) under egirdir ecological conditions. 5th Turkish Nat Hort Congress 1: 481-485.
19. Moghaddam EG, Ava SH, Akhavan S, and Hosseini S (2011). Phenological and pomological characteristics of some plum (Prunus spp.) cultivars grown in Mashhad, Iran. Crop Breed J 1(2): 105108.

20. Milosevic T and N Milosevic (2012). Main physical and chemical traits of fresh fruits of promising plum hybrids (Prunus domestica L.) from Cacak (Western Serbia). Rom Biotech Letters 17(3).

21. Walkowiak-Tomezak D, Regula $\mathrm{J}$ and Lysiak G (2008). Physico-chemical properties and antioxidant Activity of selected plum cultivars fruit. Acta Sci Pol Technol Aliment 7(4): 15-22.

22. Lysiak G (1999). Evaluation of productivity of 10 plum cultivars growing on two rootstocks. Pr. Kom. Nauk Roln. Kom. Nauk Lesn., PTPN. 87: 95-101.

23. Milosevic T and Milosevic N (2011). Quantitative analysis of the main biological and fruit quality traits of $\mathrm{f} 1$ plum genotypes (Prunus domestica L.). Acta Sci Pol Hort Cultus 10(2): 95-107.

24. Gunes M (2003). Some local varieties grown in tokat province. Pakistan $J$ applied Sci 3(5): 291-295.

25. Vangdal E, Flatland $\mathrm{S}$ and Nordbo $\mathrm{R}$ (2007). Fruit quality changes during marketing of new plum cultivars (Prunus domestica L.). Hort Sci (Prague) 34(3): 91-95. 